\title{
Incremental prognostic value of aortic stiffness in addition to myocardial ischemia by cardiac magnetic resonance imaging
}

\author{
Yodying Kaolawanich and Thananya Boonyasirinant ${ }^{*}$ (D)
}

\begin{abstract}
Background: Aortic stiffness is an independent predictor of cardiovascular (CV) events and mortality. However, no data exists for the prognosis of combined aortic stiffness and myocardial ischemia. Using cardiac magnetic resonance (CMR) imaging, we assessed the association of aortic stiffness by pulse wave velocity (PWV), myocardial ischemia, and CV events in patients with known or suspected coronary artery disease (CAD).

Methods: Velocity-encoded CMR was performed in 520 patients who had undergone adenosine stress CMR. The PWW was determined between the mid-ascending and mid-descending thoracic aorta. Patients were divided into 4 groups by PWW (higher or lower PW) and myocardial ischemia (positive or negative ischemia). Combined CV events including mortality, acute coronary syndrome, heart failure, coronary revascularization, and stroke were analyzed among the 4 groups.

Results: The median follow-up period was 46.5 months, and the median PW was $10.54 \mathrm{~m} / \mathrm{sec}$. Myocardial ischemia was positive in 199 patients (38.3\%). The group with a higher PWV and positive ischemia had the most CV events (hazard ratio $8.94, p<0.001$ ). The group with a higher PW and negative ischemia also was significantly associated with CV events (HR 2.19, $p=0.02$ ). Groups with a lower PWV-positive ischemia and a higher PW-negative ischemia showed no difference in terms of $\mathrm{CV}$ events (HR 0.60, $p=0.08$ ). Patients with myocardial ischemia who had higher PW demonstrated significantly higher event rates than those who had lower PWW (HR 2.41, $p<0.001$ ). Multivariate analysis demonstrated that myocardial ischemia and PWW were independent predictors for combined CV events (HR 2.71, $p<0.001$ and HR 2.42, $p<0.001$, respectively).
\end{abstract}

Conclusions: Stress perfusion CMR provided prognostic utility in patients with known or suspected CAD. Adding aortic stiffness to stress perfusion CMR could improve risk assessment and prediction for future CV events.

Keywords: Aortic stiffness, Cardiac magnetic resonance imaging, Myocardial ischemia, Prognosis

\section{Background}

Aortic stiffness is one of the earliest detectable indicators of adverse structural and functional changes in the vessel wall [1]. Several factors or diseases affect aortic stiffness, including increasing age [2-4], smoking [5], obesity [6], hypertension $[7,8]$, dyslipidemia $[9,10]$, impaired

\footnotetext{
* Correspondence: drthananyaa@yahoo.com

Division of Cardiology, Department of Medicine, Faculty of Medicine Siriraj Hospital, Mahidol University, 2 Wanglang Road, Bangkok Noi, Bangkok 10700, Thailand
}

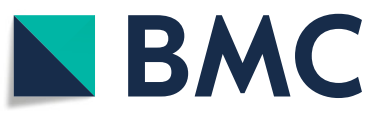

C C The Author(s). 2020 Open Access This article is licensed under a Creative Commons Attribution 4.0 International License, which permits use, sharing, adaptation, distribution and reproduction in any medium or format, as long as you give appropriate credit to the original author(s) and the source, provide a link to the Creative Commons licence, and indicate if changes were made. The images or other third party material in this article are included in the article's Creative Commons licence, unless indicated otherwise in a credit line to the material. If material is not included in the article's Creative Commons licence and your intended use is not permitted by statutory regulation or exceeds the permitted use, you will need to obtain permission directly from the copyright holder. To view a copy of this licence, visit http://creativecommons.org/licenses/by/4.0/ The Creative Commons Public Domain Dedication waiver (http://creativecommons.org/publicdomain/zero/1.0/) applies to the data made available in this article, unless otherwise stated in a credit line to the data. glucose tolerance [11], diabetes mellitus [11], metabolic syndrome [11], hyperhomocysteinemia [12], and high Creactive protein levels $[13,14]$. Aortic stiffness has been proven to be an independent predictor when evaluated with traditional risk factors for cardiovascular morbidity and mortality $[15,16]$.

Measurement of aortic stiffness can be performed by several methods, such as carotid-femoral pulse wave velocity (PWV) using a tonometer, computed tomography, or cardiac magnetic resonance (CMR) imaging. Each 
method has its advantages and disadvantages. Although carotid-femoral PWV is inexpensive and available, CMR is often preferred for several reasons. The advantages of PWV using CMR include the provision of crosssectional images covering the desired length of the aorta, a high spatial resolution, direct measurement of the aorta length without geometric assumptions of the distance (in contrast to tonometer), a lack of ionizing radiation, and the ability to evaluate other aspects of the aorta (such as aortic wall strain and deformation) $[17,18]$. Furthermore, CMR-based PWV measurements have been well validated (compared with invasive pressure recordings), and they have a high reproducibility [19].

PWV assessment can be integrated in a comprehensive CMR study for coronary artery disease (CAD) evaluation. Adenosine stress CMR, a noninvasive test for the highly sensitive and specific diagnosis of CAD [20], provides information regarding cardiac function, perfusion, and myocardial scarring. Adenosine stress CMR also offers strong evidence for the prognosis of newly developed cardiovascular events, including mortality in patients with known or suspected CAD [21]. Nevertheless, no data exists for the prognosis of combined aortic stiffness and myocardial ischemia.

This study aimed to determine whether aortic stiffness by CMR-based PWV can add the prognostic value to myocardial ischemia for the prediction of future cardiovascular events.

\section{Methods}

This retrospective, single-center study was approved by the center's institutional ethics committee. A total of 520 patients referred for adenosine stress CMR as part of the diagnosis and risk stratification of CAD were consecutively enrolled at Siriraj Hospital (Mahidol University, Bangkok, Thailand) between October 2010 and February 2014. The inclusion criteria were males or females aged 18 or older who underwent adenosine stress CMR and aortic PWV, with a follow-up period of at least 12 months following the CMR examination. Patients with (1) an incomplete CMR examination or (2) diseases of the aorta which involved PWV measurement (e.g., an aortic aneurysm) were excluded.

Detailed medical history and vital signs including blood pressure (BP) data were recorded from medical records. Further, BP was measured in a supine position by automated BP devices using appropriate cuff size, on the same day of CMR examination (approximately $10 \mathrm{~min}$ before scanning). The BP values were averaged from two measurements for each patient.

The follow-up data were collected from clinical visits, medical records, and scripted telephone interviews. Demographic data, cardiovascular risk factors, adenosine stress CMR, and PWV results were also included. Based on their PWV and ischemia results, patients were divided into 4 groups as higher or lower PWV (using mean or median), and positive or negative ischemia.

The primary outcome was to assess the combined cardiovascular outcomes (all-cause mortality, acute coronary syndrome [ACS], de novo or decompensated heart failure, coronary revascularization, and stroke) of the patients in each group. The secondary outcomes were identified as the results of each primary outcome and cardiovascular mortality. The predictors of the combined cardiovascular outcomes were analyzed. Since adenosine stress CMR results may influence decisions regarding revascularization and lead to periprocedural events or death, coronary revascularizations which occurred within 6 months of the CMR, or periprocedural events that occurred in the same admission, were not included for analysis.

\section{Magnetic resonance imaging scanning}

The CMR study was performed using a $1.5 \mathrm{~T}$ Philips Achieva XR scanner (Philips Medical Systems, Best, The Netherlands). After a scout image to locate the cardiac axis, an electrocardiogram (ECG)-triggered, breath-hold, black blood, single-shot sequence was acquired in the axial orientation for 30 slides; it covered the whole heart and thoracic aorta. The scanning parameters were echo time (TE) 24 milliseconds (ms); repetitive time (TR) $1400 \mathrm{~ms}$; refocusing flip angle $90^{\circ}$; field of view (FOV) in $\mathrm{x}$ axis $240-360 \mathrm{~mm}$; FOV in y axis $250-300 \mathrm{~mm}$; slide thickness $8 \mathrm{~mm}$; acquisition voxel size $1.75 \times 1.75 \mathrm{~mm}$; and reconstructed voxel size $0.64 \times 0.64 \mathrm{~mm}$.

The myocardial first-pass perfusion study was assessed immediately after an injection of $0.05 \mathrm{mmol} / \mathrm{kg}$ of gadolinium contrast agent (Magnevist, Bayer Schering Pharma, Berlin, Germany) beginning at 3-min of adenosine 0.56 $\mathrm{mg} / \mathrm{kg}$ infusion. The 3 short-axis slices of apical, mid, and basal left ventricular levels were acquired using an ECGtriggered, steady-state free precession, inversion-recovery, single-shot, turbo gradient-echo sequence. The image parameters were TE $1.32 \mathrm{~ms}$; TR $2.6 \mathrm{~ms}$; refocusing flip angle $50^{\circ}$; slide thickness $8 \mathrm{~mm}$; FOV $270 \mathrm{~mm}$; reconstructed FOV $320 \mathrm{~mm}$; typical matrix size $2.55 \times 2.6 \mathrm{~mm}$; and reconstructed spatial resolution $1.3 \times 1.3 \mathrm{~mm}$. Continuous ECG monitoring was performed, and 1-min-interval BP and oxygen saturation monitoring were measured.

The PWV image was acquired during the waiting period between the stress and viability studies, approximately 10 min after adenosine injection. The image was determined with the free-breathing, velocity encoded CMR (VE-CMR) technique as the through-plane flow in the mid-ascending and mid-descending thoracic aorta at the level of the pulmonary trunk. The imaging parameters were retrospective ECG-triggered; TE $3.1 \mathrm{~ms}$; TR $5.3 \mathrm{~ms}$; refocusing flip angle $12^{\circ}$; FOV in $\mathrm{x}$ axis $250 \mathrm{~mm}$; FOV in y axis $210 \mathrm{~mm}$; slide thickness $8 \mathrm{~mm}$; typical matrix size $2.0 \times 2.0 \mathrm{~mm}$; 
reconstructed spatial resolution $1.12 \times 1.12 \mathrm{~mm}$; temporal resolution 10-20 ms; and velocity encoding $170 \mathrm{~cm} / \mathrm{s}$.

\section{Adenosine stress CMR analysis}

Sixteen myocardial segments were defined for perfusion analysis (in accordance with the standard recommendation of the American Heart Association), excluding the true apex [22]. A myocardial perfusion defect was defined as positive when a perfusion delay persisted for at least 5 consecutive phases in at least 1 segment during the peak myocardial enhancement. The results were assessed by two experienced readers, and in cases of disagreement, a third experienced reader was consulted.

\section{PWV analysis}

Dedicated cardiovascular imaging software was applied for the PWV analysis. The contours of the mid-ascending and mid-descending thoracic aorta were manually drawn to achieve the flow $(\mathrm{m} / \mathrm{sec})$ at those 2 locations throughout all phases of the cardiac cycle. The corresponding flowtime curve was generated. The arrival time of the pulse wave was measured as the point of interception of the linear extrapolation of the baseline and the steep early systolic stage. The aortic path length was determined by multiplanar reconstruction of axial half-Fourier acquisition from the steady stage image. As to the reconstructed sagittal view, the path length was depicted as the centerline from the levels of the mid-ascending aorta to the mid-descending thoracic aorta, corresponding to the same level obtained in the VE-CMR.

The PWV between the mid-ascending and middescending thoracic aorta was calculated using the following formula:

$$
\mathrm{PWV}=\Delta \mathrm{x} / \Delta \mathrm{T}(\mathrm{m} / \mathrm{sec})
$$

When $\Delta \mathrm{x}$ reflected the length of the aortic path between the mid-ascending and mid-descending thoracic aorta and $\Delta \mathrm{T}$ represented the time delay between the arrival of the foot of pulse wave at those two corresponding levels (Fig. 1). The analyses of adenosine stress tests and PWV were performed independently.

\section{Intra- and inter-observer reliability}

To assess the intra- and inter-observer reliability of the PWV measurements by CMR, 50 patients were randomly selected in order to measure the variability of the first observer 4 weeks after the initial analysis, and the variability of the second independent observer, who was blinded to the initial results.

\section{Statistical analysis}

Statistical analyses were performed using IBM SPSS Statistics for Windows, version 20.0 (IBM Corp., Armonk,
NY, USA). Normally distributed continuous data were expressed as mean and standard deviation (SD). Nonnormally distributed continuous data were expressed as median and interquartile range. Categorical data were expressed as number and percentages. Normally distributed continuous data of multiple ( $>2$ ) groups were compared using one-way analysis of variance (ANOVA). Non-normally distributed continuous data of multiple $(>2)$ groups were compared using Kruskal-Wallis test. Categorical data were compared by Chi-squared or Fisher's exact test.

Cox regression was used for unadjusted and adjusted hazard ratios. Kaplan-Meier event curves for the 4 groups of patients were constructed for the combined cardiovascular outcomes of all-cause mortality, ACS, de novo or decompensated heart failure, coronary revascularization, and stroke.

To analyze the predictive value of PWV and myocardial ischemia for the combined cardiovascular outcomes, a Cox-regression analysis was performed for the assessment of univariate predictors from baseline characteristics, medications, and CMR parameters. Variables with $p$-value $<0.1$ on univariate analysis were entered into a multivariate analysis. Multivariable analysis was performed to determine independent predictors. The intra- and inter-observer reliabilities of PWV measurements were analyzed using the intraclass correlation coefficient.

The hazard ratios (HRs) and 95\% confidence intervals (CIs) for the various outcomes were calculated; a $p$-value $<0.05$ was considered as statistically significant.

\section{Results}

Comprised of 259 males and 261 females, a total of 520 patients were consecutively enrolled. Their mean age was $68.9 \pm 10.6$ years, and their baseline characteristics and CMR parameters are summarized in Table 1 . The average left ventricle ejection fraction (LVEF) was $66.7 \% \pm 14.7 \%$. The median PWV (interquartile range) was 10.54 (7.86-13.89) $\mathrm{m} / \mathrm{sec}$. The median follow-up time (interquartile range) was 46.5 (33.0-67.1) months. Using the median PWV as the cut-off value, patients were further classified according to their PWV results into those with higher PWVs $(\geq 10.54 \mathrm{~m} / \mathrm{sec})$ and lower PWVs $(<10.54 \mathrm{~m} / \mathrm{sec})$. In all, 108 patients $(20.8 \%)$ had a previous history of CAD. The adenosine stress CMR was positive in 199 cases (38.3\%). Patients were stratified into 4 groups (group 1 as lower PWV-negative ischemia, group 2 as lower PWV-positive ischemia, group 3 as higher PWV-negative ischemia, and group 4 as higher PWV-positive ischemia). Group 1 (lower PWV-negative ischemia) was the reference group for the outcome assessment, though a specific comparison was mentioned. 

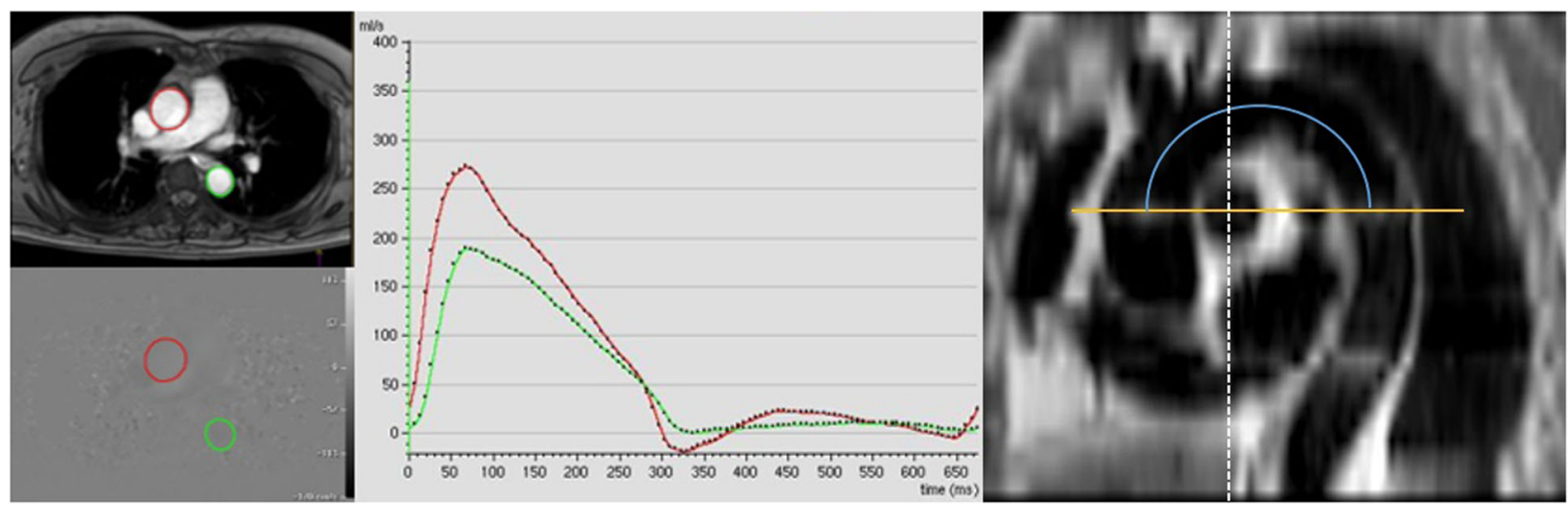

Fig. 1 Measurement of time delay between pulse waves and aortic path length. Left: Through-plane velocity-encoded cardiac magnetic resonance at the mid-ascending (red circles) and mid-descending thoracic aorta (green circles). Middle: Corresponding flow measurement at the mid-ascending (red line) and mid-descending thoracic aorta (green line). Right: The measurement of aortic path length using a multiplanar reconstructed oblique sagittal view

Table 1 Baseline characteristics and CMR parameters of all patients

\begin{tabular}{|c|c|c|c|c|c|c|}
\hline & $\begin{array}{l}\text { Group } 1 \\
\text { Lower PWV } \\
\text { Negative ischemia } \\
(n=169)\end{array}$ & $\begin{array}{l}\text { Group } 2 \\
\text { Lower PWV } \\
\text { Positive ischemia } \\
(n=91)\end{array}$ & $\begin{array}{l}\text { Group } 3 \\
\text { Higher PWV } \\
\text { Negative ischemia } \\
(n=152)\end{array}$ & $\begin{array}{l}\text { Group } 4 \\
\text { Higher PWV } \\
\text { Positive ischemia } \\
(n=108)\end{array}$ & Total & $p$-value \\
\hline Age, years & $64.6 \pm 11.7$ & $67.2 \pm 9.9$ & $73.1 \pm 8.6$ & $70.9 \pm 9.3$ & $68.9 \pm 10.6$ & $<0.001$ \\
\hline Female & $91(53.8)$ & $30(33.0)$ & $93(61.2)$ & $47(43.5)$ & $261(50.2)$ & $<0.001$ \\
\hline $\mathrm{BMl}, \mathrm{kg} / \mathrm{sqm}$ & $26.9 \pm 4.6$ & $27.1 \pm 4.6$ & $26.9 \pm 4.5$ & $25.4 \pm 3.6$ & $26.7 \pm 4.4$ & 0.01 \\
\hline \multicolumn{7}{|l|}{ Previous history } \\
\hline Hypertension & $134(79.3)$ & 76 (83.5) & $142(93.4)$ & $96(88.9)$ & $448(86.2)$ & 0.002 \\
\hline Diabetes mellitus & 75 (44.4) & $48(52.7)$ & $103(67.8)$ & $65(60.2)$ & $291(56.0)$ & $<0.001$ \\
\hline Dyslipidemia & $114(67.5)$ & 71 (78.0) & $114(75.0)$ & $80(74.1)$ & 379 (72.9) & 0.25 \\
\hline Known CAD & $12(7.1)$ & 29 (31.9) & $24(15.8)$ & $43(39.8)$ & $108(20.8)$ & $<0.001$ \\
\hline Stroke & $7(4.1)$ & $4(4.4)$ & $5(3.3)$ & $6(5.6)$ & $22(4.2)$ & 0.83 \\
\hline Current smoking & $14(8.3)$ & 27 (29.7) & $7(4.6)$ & $20(18.5)$ & $68(13.1)$ & $<0.001$ \\
\hline \multicolumn{7}{|l|}{ Medications } \\
\hline Aspirin & 67 (39.6) & $55(60.4)$ & $66(43.4)$ & $70(64.8)$ & $258(49.6)$ & $<0.001$ \\
\hline Beta blocker & $75(44.4)$ & $48(52.7)$ & 78 (51.3) & $56(51.9)$ & $257(49.4)$ & 0.46 \\
\hline Calcium channel blocker & $50(29.6)$ & $26(28.6)$ & $55(36.2)$ & $33(30.6)$ & $164(31.5)$ & 0.53 \\
\hline ACEI or ARB & $62(36.7)$ & $40(44.0)$ & $77(50.7)$ & $57(52.8)$ & $236(45.4)$ & 0.03 \\
\hline Statin & $83(49.1)$ & $49(53.8)$ & $80(52.6)$ & $74(68.5)$ & $286(55.0)$ & 0.01 \\
\hline \multicolumn{7}{|l|}{ Parameter } \\
\hline Systolic BP, mmHg & $131.8 \pm 18.4$ & $132.3 \pm 18.0$ & $139.5 \pm 19.2$ & $144.6 \pm 21.5$ & $136.8 \pm 19.9$ & $<0.001$ \\
\hline Diastolic BP, mmHg & $74.4 \pm 10.9$ & $72.1 \pm 12.4$ & $72.1 \pm 12.6$ & $72.6 \pm 12.6$ & $72.9 \pm 12.0$ & 0.282 \\
\hline Pulse pressure, $\mathrm{mmHg}$ & $57.3 \pm 15.6$ & $60.2 \pm 16.2$ & $67.5 \pm 17.2$ & $71.7 \pm 20.7$ & $63.8 \pm 18.2$ & $<0.001$ \\
\hline Heart rate, bpm & $76.9 \pm 13.4$ & $75.2 \pm 12.4$ & $77.5 \pm 14.8$ & $77.5 \pm 13.8$ & $76.9 \pm 13.7$ & 0.54 \\
\hline LVEF, \% & $68.2 \pm 12.5$ & $61.1 \pm 16.2$ & $72.9 \pm 9.5$ & $60.6 \pm 18.1$ & $66.7 \pm 14.7$ & $<0.001$ \\
\hline $\mathrm{PW}, \mathrm{m} / \mathrm{sec}$ & $7.73(6.64-8.94)$ & $8.46(7.08-9.43)$ & $13.99(12.35-17.59)$ & $13.44(11.57-16.31)$ & $10.54(7.86-13.89)$ & $<0.001$ \\
\hline
\end{tabular}

Values are $\mathrm{n}(\%)$, mean $\pm \mathrm{SD}$, or median (interquartile range). Bold values are statistically significant

$A C E I$ Angiotensin-converting enzyme inhibitors, $A R B$ Angiotensin-receptor blockers, $B M I$ Body mass index, CAD Coronary artery disease, $B P$ Blood pressure, $L V E F$ Left ventricular ejection fraction, PWV Pulse wave velocity, SD Standard deviation 


\section{Combined cardiovascular outcomes}

The cumulative event rates for the composite outcomes of all-cause mortality, ACS, de novo or decompensated heart failure, coronary revascularization, and stroke in each group are presented in Table 2. The overall combined endpoints were 116 events (22.3\%).

Using the group 1 (lower PWV-negative ischemia) as the reference group, the group 4 (higher PWV-positive ischemia) had the significantly worst outcomes for the combined endpoints (HR 8.94, 95\% CI 4.95-16.14, $p<0.001$ ). The group 2 (lower PWV-positive ischemia) and the group 3 (higher PWV-negative ischemia) also showed significantly increased the combined endpoints (HR 3.67, 95\% CI 1.91-7.06, $p<0.001$, and HR 2.19, 95\% CI 1.13-4.20, $p=0.02$, respectively). Remarkably, there were no significant differences between the group 2 and 3 in terms of the event rates (using the group 2 as the reference: HR 0.60, 95\% CI 0.34-1.05, $p=0.08$ ). Additionally, patients with myocardial ischemia (groups 2 and 4) who had higher PWV (group 4) demonstrated significantly higher event rates than those who had lower PWV (group 2) (using group 2 as the reference: HR $2.41,95 \%$ CI 1.49-3.88, $p<0.001)$.

After adjusting for traditional risk factors and LVEF, the group 2-4 maintained significant association with combined cardiovascular outcomes (Table 2). KaplanMeier survival curves for combined cardiovascular outcomes are shown in Fig. 2.

\section{All-cause and cardiovascular mortality}

During the follow-up period, 28 total deaths including 10 cardiovascular deaths were recorded. Cardiovascular disease was the leading cause of mortality (35.7\%), followed by infection (28.6\%) and cancer (21.4\%). The groups 2 and 4 with positive ischemia by adenosine stress CMR had the highest mortality rate (Table 2 ).

\section{ACS}

ACS was defined as the composite of unstable angina, nonST-segment elevation myocardial infarction (NSTEMI), and ST-segment elevation myocardial infarction (STEMI). There were 41 cases of ACS (unstable angina $=10$, NSTEMI $=25$, and STEMI $=6), 30(73 \%)$ of which were in the higher PWV groups (group 3 and 4). The KaplanMeier event curves for the ACS cases in each group are illustrated in Fig. 3.

\section{Heart failure}

The leading cause of cardiovascular death was de novo or decompensated heart failure; of the 54 events recorded, 43 (80\%) required hospital admission. The higher PWV groups (group 3 and 4) were associated with an increased rate of de novo or decompensated heart failure than the groups with a lower PWV (group
1 and 2) (HR 2.49, 95\% CI 1.40-4.42, $p=0.002$ ). The Kaplan-Meier curves for the heart failure events are presented in Fig. 4.

\section{Coronary revascularization}

Coronary revascularizations occurring at least 6 months after the CMR examination were included in the combined endpoint. There were 29 coronary revascularizations, including 20 with percutaneous coronary intervention and 9 requiring coronary bypass grafting. Twenty-three of those revascularizations were in the higher-PWV groups (group 3 and 4).

\section{Stroke}

There were 14 strokes during the follow-up period. Most stroke events (11 from 14) was in the higher PWV group (3 and 4). All strokes were ischemic in origin, and most patients recorded a good recovery without major morbidity.

\section{Univariate and multivariate analyses}

The univariate and multivariable analyses to predict the combined cardiovascular outcomes are shown in Table 3. The univariate analysis revealed age, body mass index, known CAD, LVEF, myocardial ischemia, and PWV as predictors, while the multivariate analysis revealed only LVEF (HR 1.26, 95\% CI 1.12-1.42, $p<0.001$ [per $10 \%$ decrement]), myocardial ischemia (HR 2.71, 95\% CI $1.75-4.21, p<0.001$ ), and PWV (HR 2.42, 95\% CI 1.64$3.57, p<0.001)$ as independently associated with combined cardiovascular events.

\section{Intra- and inter-observer reliability}

Excellent intra- and inter-observer reliabilities were demonstrated for PWV measurements by CMR. For the 50 randomly-selected patients, the mean $\mathrm{PWV} \pm \mathrm{SD}$ values were $10.72 \pm 5.95 \mathrm{~m} / \mathrm{sec}$ and $10.79 \pm 6.13 \mathrm{~m} / \mathrm{sec}$ $(\mathrm{r}=0.99 ; p<0.001)$ for the first observer in the initial analysis and 4 weeks later, respectively, and $10.55 \pm 5.12$ $\mathrm{m} / \mathrm{sec}(\mathrm{r}=0.98 ; p<0.001)$ for the second observer in the initial analysis (Fig. 5).

\section{Discussion}

The three main findings of this study were 1) aortic stiffness measured by CMR independently predicted composite cardiovascular events in patients with known or suspected CAD underwent adenosine stress test; 2) the presence of inducible myocardial ischemia was a powerful predictor for cardiovascular events; and 3) the combination of aortic stiffness and myocardial ischemia provided significant improvement of prognostic predictions. 


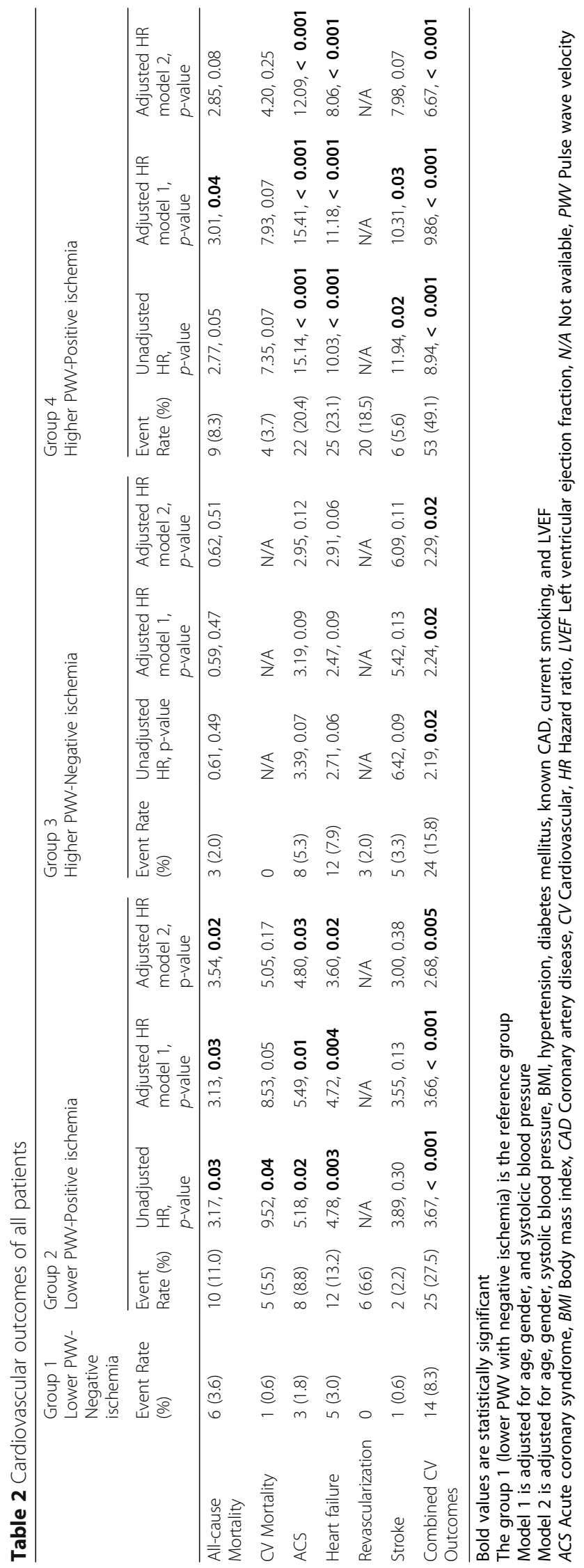




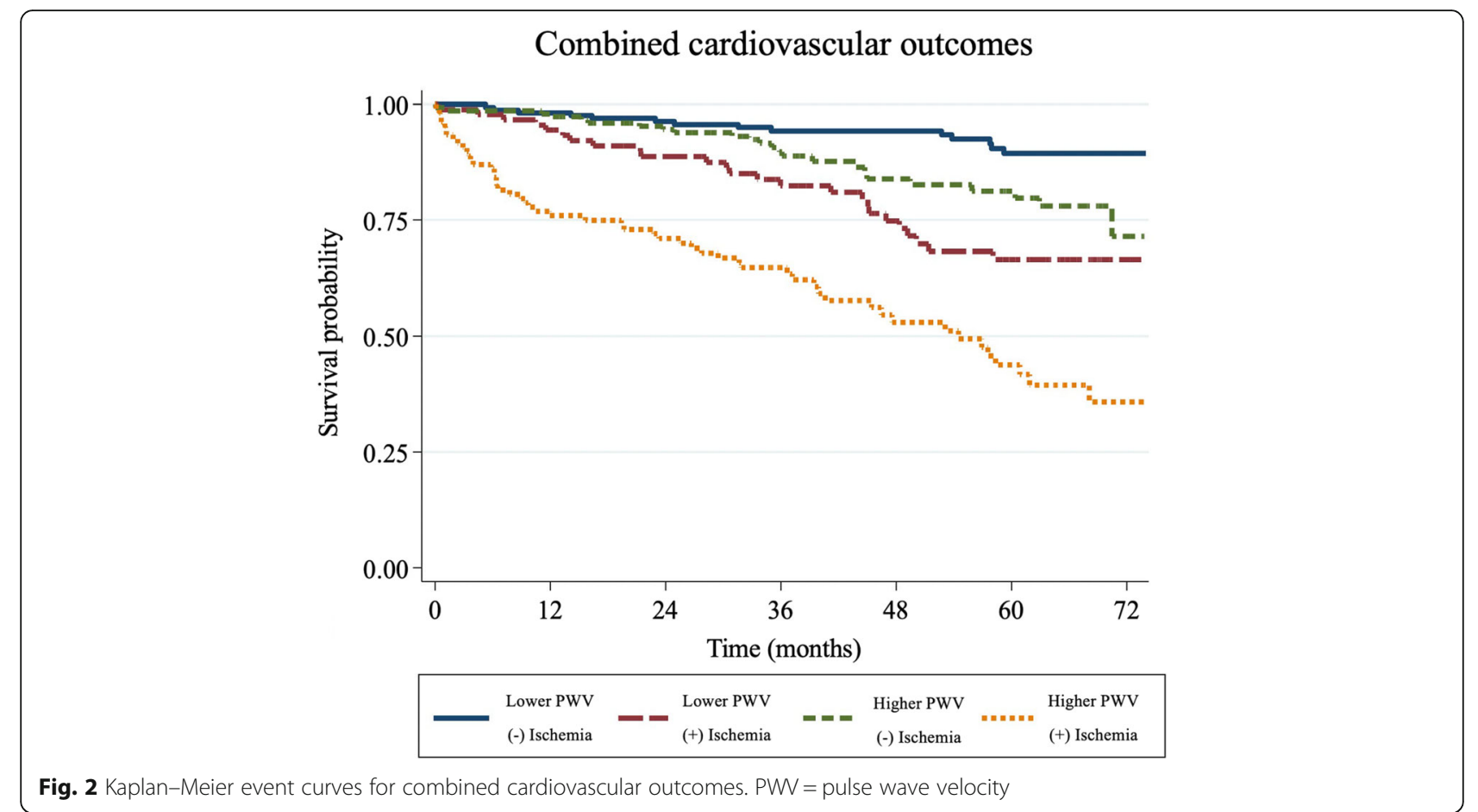

\section{Aortic stiffness}

Arterial stiffness refers to alterations of medial properties leading to reduced distensibility of the arterial wall. Many factors and diseases influence arterial stiffness, including aging [2-4], hypertension [7, 8], diabetes mellitus [11], dyslipidemia $[9,10]$, and smoking [5].
Several functional and structural changes contribute to arterial stiffness, for instance, high BP, impaired smooth muscle function, impaired endothelium-dependent dilation, increased collagen content expression, and decreased elastin content. Furthermore, numerous potentials signaling events contribute to age- and disease-related arterial

\section{Acute coronary syndrome}

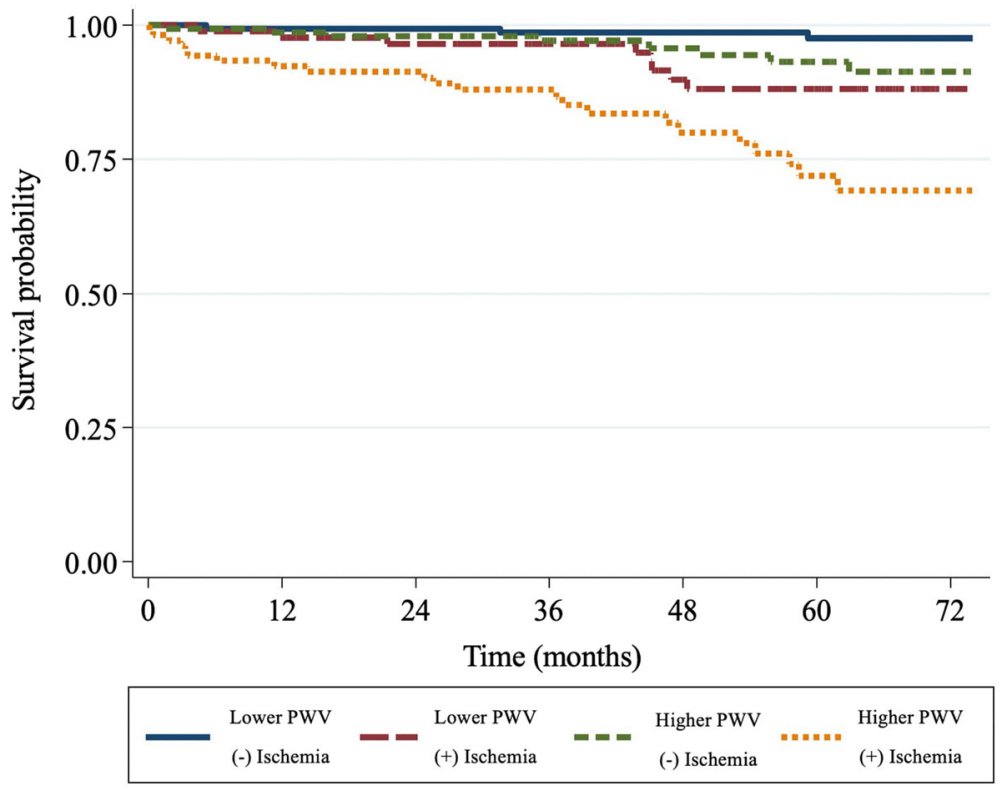

Fig. 3 Kaplan-Meier event curves for acute coronary syndrome. PWV = pulse wave velocity 


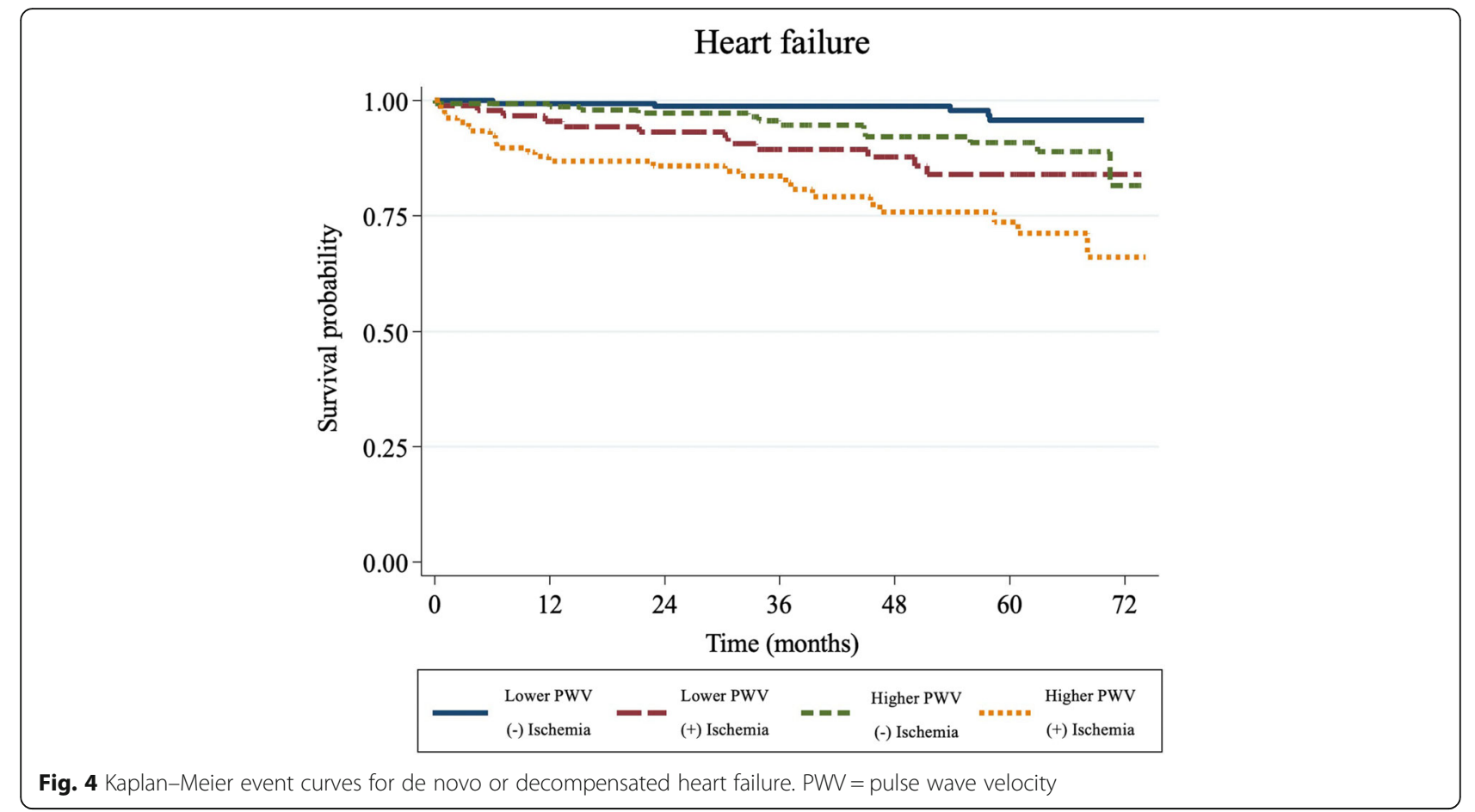

stiffness, such as oxidative stress, inflammation, and decreased expression of endothelial nitric oxide synthase activity. Increased aortic stiffness has been established in various cardiovascular diseases and metabolic abnormalities.

Carotid-femoral PWV using a tonometer is generally accepted as a simple, noninvasive, and inexpensive method to measure arterial stiffness. This technique is the measure used in most clinical studies and is a strong predictor of cardiovascular events $[6,15,16]$. However, it has some limitations. This method requires the assumed measurement of the aortic distance from the carotid to femoral arteries. Most studies measure this distance with tape over the surface of the body, leading to an overestimation of the real distance traveled by the pulse wave $[6,15,16]$.

Table 3 Univariate and multivariate analysis of variables for combined cardiovascular outcomes

\begin{tabular}{|c|c|c|c|c|}
\hline \multirow[t]{3}{*}{ Variables } & \multicolumn{4}{|c|}{ Combined cardiovascular outcomes } \\
\hline & \multicolumn{2}{|c|}{ Univariate analysis } & \multicolumn{2}{|c|}{ Multivariate analysis } \\
\hline & $\mathrm{HR}(95 \% \mathrm{Cl})$ & $p$-value & $\mathrm{HR}(95 \% \mathrm{Cl})$ & $p$-value \\
\hline Age (per 10 years increment) & $1.17(0.99-1.41)$ & 0.08 & $1.10(0.91-1.33)$ & 0.34 \\
\hline Male & $1.16(0.81-1.67)$ & 0.42 & - & - \\
\hline Body mass index & $0.96(0.91-0.99)$ & 0.04 & $0.98(0.94-1.03)$ & 0.50 \\
\hline Hypertension & $1.36(0.76-2.42)$ & 0.29 & - & - \\
\hline Diabetes mellitus & $1.24(0.86-1.80)$ & 0.25 & - & - \\
\hline Dyslipidemia & $1.18(0.77-1.82)$ & 0.45 & - & - \\
\hline Known coronary artery disease & $2.35(1.59-3.48)$ & $<0.001$ & $1.48(0.98-2.24)$ & 0.06 \\
\hline Stroke & $1.19(0.52-2.71)$ & 0.68 & - & - \\
\hline SBP (per 10 mmHg increment) & $1.01(0.92-1.11)$ & 0.77 & - & - \\
\hline LVEF (per 10\% decrement) & $1.37(1.24-1.52)$ & $<0.001$ & $1.26(1.12-1.42)$ & $<0.001$ \\
\hline Myocardial ischemia & $4.01(2.72-5.91)$ & $<0.001$ & $2.71(1.75-4.21)$ & $<0.001$ \\
\hline $\mathrm{PWV} \geq 10.54 \mathrm{~m} / \mathrm{sec}$ & $2.42(1.64-3.56)$ & $<0.001$ & $2.42(1.64-3.57)$ & $<0.001$ \\
\hline
\end{tabular}

Bold values are statistically significant

CI Confidence interval, HR Hazard ratio, LVEF Left ventricular ejection fraction, PWV Pulse wave velocity, SBP Systolic blood pressure 

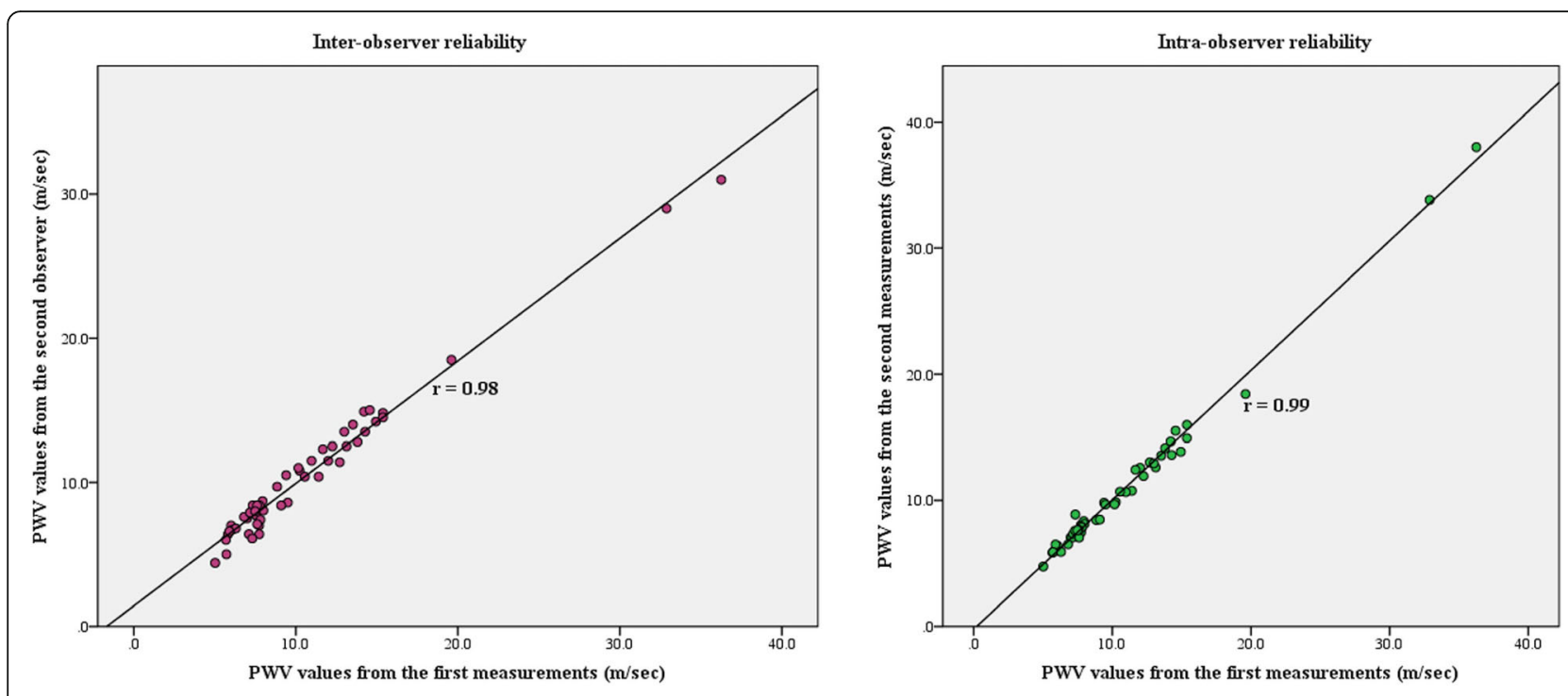

Fig. 5 Inter- (left) and intra-observer (right) reliability of PWV measurements. PWV = pulse wave velocity

PWV measurement using CMR is one of the preferred methods for evaluation of arterial stiffness, giving high spatial resolution without ionizing radiation. This technique can assess PWV accurately across any segment of aorta, but the level of the mid-ascending and middescending aorta was chosen due to the corresponding location of the heart in CMR examination. Moreover, CMR can measure the distance of the aorta without geometrical assumptions, unlike carotid-femoral PWV using a tonometry. The PWV measured by CMR in our study demonstrated excellent images with significantly high reliability comparable to the previous studies [19].

\section{Relationship between aortic stiffness and myocardial ischemia}

The pathophysiology pathway of increased arterial stiffness and myocardial ischemia is a complex issue. One of the explanations could be the translation of the arterial wave reflection progressively from diastole into late systole [23].

Arterial stiffness causes an early arrival of wave reflections in systole instead of diastole and, thus, increases the systolic afterload and reduces the diastolic coronary perfusion pressure. As a result of this pathophysiological changes, arterial stiffness may cause an ischemic heart injury through a reduction in the subendocardial oxygen supply and increase in oxygen demand. However, a recent meta-analysis demonstrated that the arterial reflection times of most subjects were well within systole rather than diastole [24]. This meta-analysis highlighted the concept of the mechanism of BP change with aging. Thus, it appears that arterial stiffness contributes to myocardial ischemia through the loss of arterial compliance itself rather than a change in the reflecting time.
Nevertheless, this issue remains a topic of debate and requires further researches.

With regard to CAD, aortic stiffness is associated with a broad range of patients, from apparently healthy subjects to those with cardiovascular risks and stable CAD, to postcoronary intervention [25-28]. One clinical study demonstrated that increased aortic stiffness using brachial-ankle PWV measured by volume-plethysmography was an independent predictor of 3-year cardiovascular event-free survival in patients with established CAD [28]. However, no data on the prognosis using CMR in patients with known or suspected CAD combined with aortic stiffness and myocardial ischemia has been presented.

Previous studies have shown that myocardial ischemia is one of the most important predictors of future hard cardiac events $[29,30]$. This statement was supported by our results. We found that myocardial ischemia by CMR was the strongest predictor of combined cardiovascular outcomes. In addition, the result also demonstrated almost 2.5-times increased in composite endpoints in patients who had higher PWV with positive ischemia compare to the group of lower PWV-positive ischemia. Therefore, the potential role of aortic stiffness combination with myocardial ischemia to improve the risk stratification beyond myocardial ischemia alone was highlighted in this study.

\section{Using CMR to comprehensive assessment of CAD and aortic stiffness}

The utility of CMR in the evaluation of CAD is increasingly being recognized. In particular, vasodilator stress perfusion CMR and viability assessment by delayed enhancement technique. The accuracy of the adenosine stress CMR for diagnosis of CAD is substantially high with sensitivity and specificity of 89 and $87 \%$, respectively [21]. 
Aortic stiffness using PWV can be performed as a part of a comprehensive stress perfusion CMR protocol. In our study, PWV was measured during the waiting period between the stress and viability studies; the non-breathhold technique proved convenient for patients. The PWV images was acquired after adenosine injection approximately $10 \mathrm{~min}$. Even if adenosine may affect the arterial compliance, given its very rapid half-life $(<10 \mathrm{~s})$, this effect did not alter PWV measurement in our study.

According to the primary study objective, aortic stiffness assessed by CMR was determined as a potential risk marker for cardiovascular disease with high accuracy and reproducibility.

\section{Limitations}

There were some study limitations. Firstly, this study was retrospective in its methodology. Some confounding factors cannot be totally eliminated due to the nature of retrospective study. In addition, no standard, cut-off level was currently used for the PWV quantification. Finally, variations in heart rates may have resulted in slightly different velocity waveforms between cardiac cycles, resulting in errors in the PWV measurements. However, a prior validation study of PWV assessed by CMR determined agreement between invasive intraaortic pressure measurements [19].

\section{Clinical application}

The addition of aortic stiffness to myocardial ischemia results improves the prognostic prediction of cardiovascular events. The combination of aortic stiffness and adenosine stress test results might become an integral part of clinical risk stratification and the monitoring of therapy.

\section{Perspectives}

Aortic stiffness can be detected long before the clinical appearance of cardiovascular diseases. From our results, measurement of aortic stiffness can be performed along with an assessment of myocardial ischemia, thereby improving cardiovascular risk stratification.

There has been some evidence that has suggested that antihypertensive drugs are beneficial in reducing aortic stiffness and thus might modify cardiovascular events beyond a decrease in BP [31]. This aspect requires further investigation.

\section{Conclusions}

This retrospective study demonstrated that the addition of aortic stiffness to myocardial ischemia could improve the prognostic prediction of $\mathrm{CV}$ events. The combination of aortic stiffness and adenosine stress test might become an integral component for risk stratification in CAD.

\section{Abbreviations}

ACS: Acute coronary syndrome; BP: Blood pressure; CAD: Coronary artery disease; Cl: Confidence interval; CMR: Cardiac magnetic resonance imaging; CV: Cardiovascular; ECG: Electrocardiography; FOV: Field of view; HR: Hazards ratio; LVEF: Left ventricular ejection fraction; NSTEMI: Non-ST-segment elevation myocardial infarction; PWV: Pulse wave velocity; SD: Standard deviation; STEMI: ST-segment elevation myocardial infarction; T: Tesla; TE: Echo time; TR: Repetitive time; VE-CMR: Velocity-encoded cardiac magnetic resonance imaging

\section{Acknowledgements}

The authors would like to thank Miss Khemajira. Karaketklang, M.P.H. and Miss Michele A. Parker, M.S. for statistical assistance.

\section{Authors' contributions \\ YK: conception; design; analysis and interpretation of data; drafting of the manuscript; critical revision of the manuscript for important intellectual content; and final approval of the manuscript. TB: conception; design; analysis and interpretation of data; drafting of the manuscript; and final approval of the manuscript.}

Funding

Faculty of Medicine Siriraj Hospital, Mahidol University.

Availability of data and materials

The datasets used and/or analyzed during the current study are available from the corresponding author on reasonable request.

\section{Ethics approval and consent to participate}

This study was approved by Siriraj Institutional Review Board, Faculty of Medicine Siriraj Hospital, Mahidol University. The need for consent was waived by the board due to its retrospective nature and as all personal identifying information was obliterated.

Consent for publication

Not applicable.

\section{Competing interests}

The authors declare that they have no competing interests.

Received: 29 January 2019 Accepted: 24 May 2020

Published online: 11 June 2020

References

1. Cecelja M, Chowienczyk P. Role of arterial stiffness in cardiovascular disease. JRSM Cardiovasc Dis. 2012;1:1.

2. Laurent $S$, Boutouyrie $P$, Lacolley P. Structural and genetic bases of arterial stiffness. Hypertension. 2005;45:1050-5.

3. Shepherd JT, Abboud FM. Handbook of physiology. Vol III, part I. Peripheral circulation and organ blood flow. Baltimore: Williams \& Wilkins; 1983. p. 65-102.

4. Lakatta EG, Levy D. Arterial and cardiac ageing: major shareholders in cardiovascular disease enterprises: part I: ageing arteries: a set up for vascular disease. Circulation. 2003;107:139-46.

5. Kool MJ, Hoeks AP, Struijker-Boudier HA, Reneman RS, Van Bortel LM. Shortand long-term effects of smoking on arterial wall properties in habitual smokers. J Am Coll Cardiol. 1993;22:1881-6.

6. Ferreira I, Henry RM, Twisk JW, van Mechelen W, Kemper HC, Stehouwer CD. Amsterdam Growth, Health Longitudinal Study. The metabolic syndrome, cardiopulmonary fitness, and subcutaneous trunk fat as independent determinants of arterial stiffness: the Amsterdam Growth and health longitudinal Study. Arch Intern Med. 2005;165:875-82.

7. O' Rourke MF. Arterial Function in Health and Disease. Edinburgh: Churchill; 1982.

8. Simon AC, Levenson J, Bouthier J, Safar ME, Avolio AP. Evidence of early degenerative changes in large arteries in human essential hypertension. Hypertension. 1985;7:675-80.

9. Aggoun Y, Bonnet D, Sidi D, Girardet J, Brucker E, Polak M, Safar ME, Levy BI. Arterial mechanical changes in children with familial hypercholesterolemia. Arterioscler Thromb Vasc Biol. 2000;20:2070-5. 
10. Wilkinson IB, Prasad K, Hall IR, Thomas A, MacCallum H, Webb DJ, Frenneaux MP, Cockcroft JR. Increased central pulse pressure and augmentation index in subjects with hypercholesterolemia. J Am Coll Cardiol. 2002;39:1005-11.

11. Schram MT, Henry RM, van Dijk RA, Kostense PJ, Dekker JM, Nijpels G, Heine RJ, Bouter LM, Westerhof N, Stehouwer CD. Increased central artery stiffness in impaired glucose metabolism and type 2 diabetes: the Hoorn Study. Hypertension. 2004;43:176-81.

12. Bortolotto LA, Safar ME, Billaud E, Lacroix C, Asmar R, London GM, Blacher J. Plasma homocysteine, aortic stiffness, and renal function in hypertensive patients. Hypertension. 1999;34:837-42.

13. Booth $A D$, Wallace $S$, McEniery CM, Yasmin BJ, Jayne DR, Wilkinson IB. Inflammation and arterial stiffness in systemic vasculitis:a model of vascular inflammation. Arthritis Rheum. 2004;50:581-858.

14. Yasmin MECM, Wallace S, Mackenzie IS, Cockcroft JR, Wilkinson IB. C-reactive protein is associated with arterial stiffness in apparently healthy individuals. Arterioscler Thromb Vasc Biol. 2004;24:969-74.

15. Sutton-Tyrrell K, Najjar SS, Boudreau RM, et al. Elevated aortic pulse wave velocity, a marker of arterial stiffness, predicts cardiovascular events in wellfunctioning older adults. Circulation. 2005;111:3384-90.

16. Mattace-Raso FU, van der Cammen TJ, Hofman A, et al. Arterial stiffness and risk of coronary heart disease and stroke: the Rotterdam Study. Circulation. 2006;113:657-63.

17. Mackenzie IS, Wilkinson IB, Cockcroft JR. Assessment of arterial stiffness in clinical practice. QJM. 2002;95:67-74.

18. Cavalcante JL, Lima JA, Redheuil A, Al-Mallah MH. Aortic stiffness: current understanding and future directions. J Am Coll Cardiol. 2011;57:1511-22.

19. Grotenhuis HB, Westenberg JJM, Steendijk $P$, et al. Validation and reproducibility of aortic pulse wave velocity as assessed with velocityencoded MRI. J Magn Reson Imaging. 2009;30:521-6.

20. Klem I, Heitner JF, Shah DJ, et al. Improved detection of coronary artery disease by stress perfusion cardiovascular magnetic resonance with the use of delayed enhancement infarction imaging. J Am Coll Cardiol. 2006;47: 1630-8

21. Jahnke C, Nagel E, Gebker R, et al. Prognostic value of cardiac magnetic resonance stress tests: adenosine stress perfusion and dobutamine stress wall motion imaging. Circulation. 2007;115:1769-76.

22. Cerqueira MD, Weissman NJ, Dilsizian V, et al. Standardized myocardial segmentation and nomenclature for tomographic imaging of the heart: a statement for healthcare professionals from the cardiac imaging committee of the council on clinical cardiology of the American heart association. Circulation. 2002;105(4):539-42.

23. Laurent S, Cockcroft J, Van Bortel L, Boutouyrie P, Giannattasio C, Hayoz D, et al. Expert consensus document on arterial stiffness: methodological issues and clinical applications. Eur Heart J. 2006;27(21):2588-605.

24. Baksi AJ, Treibel TA, Davies JE, Hadjiloizou N, Foale RA, Parker KH, et al. A meta-analysis of the mechanism of blood pressure change with aging. J Am Coll Cardiol. 2009;54(22):2087-92.

25. Feistritzer H-J, Klug G, Reinstadler SJ, Mair J, Seidner B, Mayr A, et al. Aortic stiffness is associated with elevated high-sensitivity cardiac troponin $T$ concentrations at a chronic stage after ST-segment elevation myocardial infarction. J Hypertens. 2015;33:1970-6.

26. Prskalo Z, Brizić I, Markota D, Markota I, Boban M, Tomic M, Starcevic B. Arterial stiffness in patients with coronary artery disease: relation with instent restenosis following percutaneous coronary intervention. BMC Cardiovasc Disord. 2016;16:128.

27. Maroules CD, Khera A, Ayers C, Goel A, Peshock RM, Abbara S, King KS Cardiovascular outcome associations among cardiovascular magnetic resonance measures of arterial stiffness: the Dallas heart study. J Cardiovasc Magn Reson. 2014;16:33.

28. Nakamura M, Yamashita T, Yajima J, et al. Brachial-ankle pulse wave velocity as a risk stratification index for the short-term prognosis of type 2 diabetic patients with coronary artery disease. Hypertens Res. 2010;33:1018-24.

29. Iskander S, Iskandrian AE. Risk assessment using single-photon emission computed tomographic technetium-99m sestamibi imaging. J Am Coll Cardiol. 1998;32(1):57-62.

30. Hachamovitch R, Berman DS, Shaw LJ, Kiat H, Cohen I, Cabico JA, et al. Incremental prognostic value of myocardial perfusion single photon emission computed tomography for the prediction of cardiac death: differential stratification for risk of cardiac death and myocardial infarction. Circulation. 1998;97(6):535-43.
31. Protogerou AD, Stergiou GS, Vlachopoulos C, et al. The effect of antihypertensive drugs on central blood pressure beyond peripheral blood pressure. Part II: evidence for specific class-effects of antihypertensive drugs on pressure amplification. Curr Pharm Des. 2009;15:272-89.

\section{Publisher's Note}

Springer Nature remains neutral with regard to jurisdictional claims in published maps and institutional affiliations.
Ready to submit your research? Choose BMC and benefit from:

- fast, convenient online submission

- thorough peer review by experienced researchers in your field

- rapid publication on acceptance

- support for research data, including large and complex data types

- gold Open Access which fosters wider collaboration and increased citations

- maximum visibility for your research: over $100 \mathrm{M}$ website views per year

At BMC, research is always in progress.

Learn more biomedcentral.com/submissions 